\title{
Identifying the Best Coach by an Improved AHP Model
}

\author{
Jinming Xing, ${ }^{1}$ Chang Zhao, ${ }^{2}$ Xiao-liang Wang, ${ }^{3}$ and Nan Xiang ${ }^{2}$ \\ ${ }^{1}$ School of Physical Education, Northeast Normal University, Changchun 130024, China \\ ${ }^{2}$ Faculty of Chemical, Environmental and Biological Science and Technology, Dalian University of Technology, Dalian 116024, China \\ ${ }^{3}$ Department of Electronics \& Information Engineering, Dalian University of Technology, Dalian 116024, China
}

Correspondence should be addressed to Jinming Xing; 122599861@qq.com

Received 14 April 2014; Revised 7 June 2014; Accepted 7 June 2014; Published 17 July 2014

Academic Editor: Fuding Xie

Copyright (C) 2014 Jinming Xing et al. This is an open access article distributed under the Creative Commons Attribution License, which permits unrestricted use, distribution, and reproduction in any medium, provided the original work is properly cited.

\begin{abstract}
The evaluation of coaches in college ball game is very essential, since a better choice of coaches will help get more scores for a team. In this paper, a simple, however, comprehensive model is proposed to evaluate college coaches of a century. By comparing the compressive index of different coaches in the evaluation, the top five coaches are found with their influence over time discussed either. Based on data of certain sport, a basic model is introduced. The superimposed application of the model makes it possible for the data of different levels to deliver proper evaluation. And by optimizing the data, we can provide precise evaluation items and authentic synthetic scores for each coach. Among their applications, the models of various sports are obtained in which relatively accurate results are still available. Although a number of deficiencies were disclosed by multiple expansions, this model is still simple, accurate, and valuable to select the best coaches.
\end{abstract}

\section{Introduction}

Volumes have explored the success of the sport teams or the related competitive pattern based on simple data analysis and statistics [1,2], however, to some extent, with the problem of inaccuracy. Moreover, through such simple analysis, we cannot evaluate the coaches in multiple aspects accurately [3, 4]. In order to address the shortcomings above, we optimize our AHP model and build a new evaluating system [5].

As an important member of the sports team, coaches played a role of selecting outstanding athletes and drawing up the whole plans for their training $[6,7]$. Thus, the quality of coaches is crucial to the development of the team [8-10]. Therefore, building appropriate models in selecting the best coaches is of great importance and the process can be as follows.

Firstly, we determine the basic model as the basis of our work. After the analysis upon the subject, we find that this can be evaluated by different indexes-qualitative and quantitative $[5,11]$. Besides, we also find that it is so hard to build specific differential or algebraic formula due to the failing quantization and uniform of each index. However, the model of analytic hierarchy process (AHP) can avoid the weakness of relation between each index [12-14]. We change the question into specific conditions which can evaluate the objectives. As to those conditions of the same kind, we make our judgments on their importance level and build matrix with them. By calculating the largest eigenvalue and eigenvector of this matrix, we get the weight of each evaluating condition and then achieve the appraisal of the greatest college coaches with all the work above [5].

After that, we define, screen out, and classify the specific conditions for the evaluation. In practice, we build a submodel firstly to test the influence of gender and time axis which are both not clear yet. During our test on time axis, we screen out secondary index to build statistics model which shows the relationship between times and team intuitively. This model also gives us a clear vision of the changing of American basketball competence. It is easy to find that coaches who work in an environment of higher competence tend to have higher professional level. At the meantime, we select index sharing the same level with time to finish the whole analysis hierarchy process.

Finally, we use our model to do the appraisal of the ten greatest $\mathrm{CBC}$ and more persuasive top five in them after more indexes being added in the model. With the existing data, this model can be applied to different sports to select the greatest 


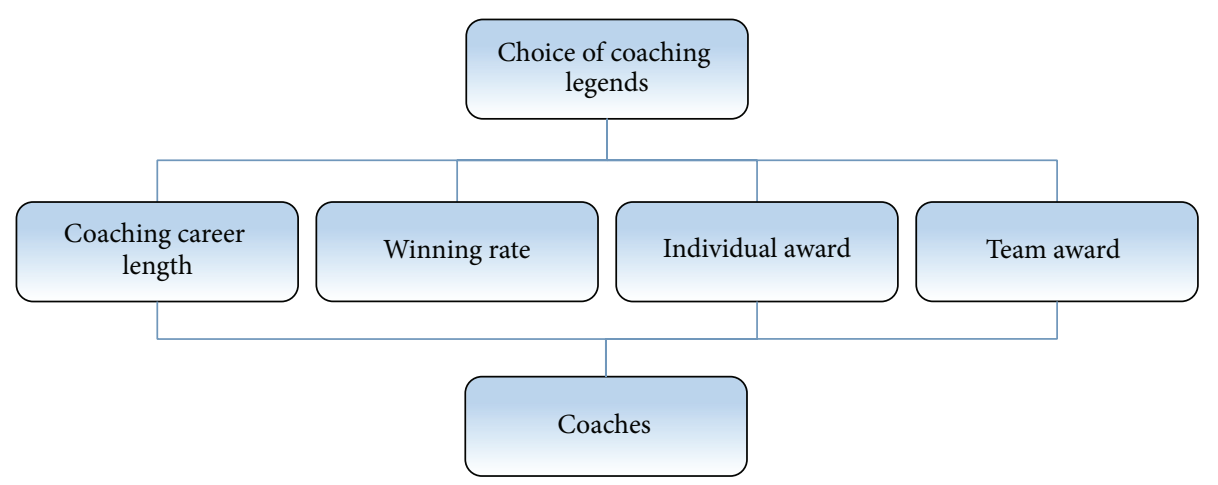

FIGURE 1: General graph model.

coaches in different fields. However, the comparison between results of the model and common sense can help us find that the results do not seem to be so accurate which means more analysis is needed to contribute to the optimization.

\section{Model Building}

The goal of our team is quite clear which is to look for "the best of all time college coach" of both male and female for the previous century. This paper introduces a quantifying model with factors that have already been precisely classified. The model can be used to evaluate coaches on their excellence directly. It contains impersonal data such as time, winning rate, and game award and, at the meantime, personal factors such as experiment experience which works in importance classification process.

Figure 1 shows our model intuitively.

2.1. Assumptions. Other factors such as individual personalities do not influence our results [11].

The assuming ranking of the factors is accurate while creating and using the model [15].

2.2. Factors. In this part, we consider as many as possible direct factors that influence coaches' professional level and career awards, among which choose four as key indexes, which are coaching career length, winning rate, individual award, and team award [16].

Winning rate refers to the ratio between NACC team quantity in middle year of objective's career [17] and average quantity of nearly a century to judge the average intense level of competence in this field $[18,19]$. Optimization of the winning rate is achieved with algebraic expression, fitness of winning rate, and average intense level of competence using a certain coefficient [20]. We find that time axis plays an important role in this process. With the passage of time, the increase of team quantity indicates the increase in winning rate under objective coaches. As for this question, analysis hierarchy process does not only split practical and abstract problems into certain specific evaluating index but also show how index of low level influences the chain transition through computing index of different level.

Moreover, we can achieve the comparability between each decisive factor by quantizing and sequencing the importance
TABLE 1: Variable definitions mentioned in model 1.

\begin{tabular}{lc}
\hline Items & Characters \\
\hline Year & $x$ \\
Team quantity & $y$ \\
Average team quantity in near a century & $Y$ \\
Participation times in middle year of coach's career & $Z$ \\
Winning rate & $P$ \\
\hline
\end{tabular}

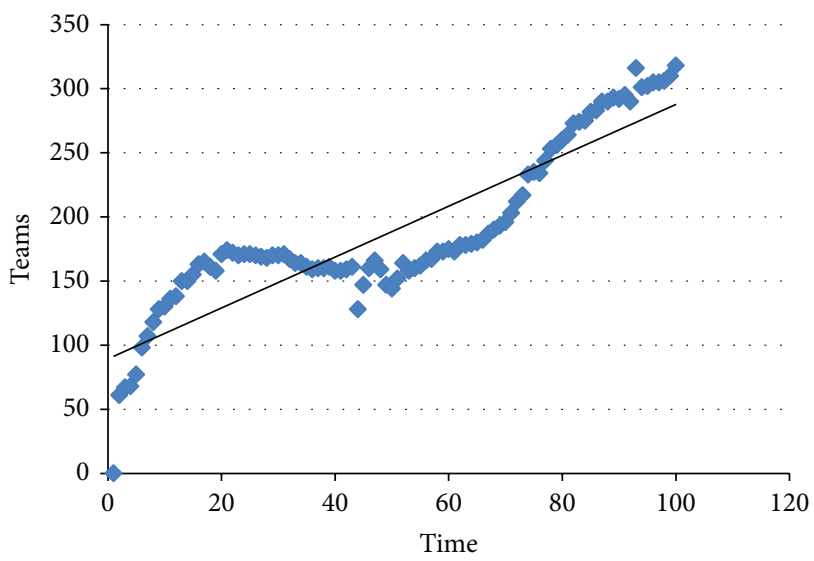

FIGURE 2: Curve of year and teams (basketball).

of indexes of the same class. The model we introduced adds more persuasion to index of high level with integrative use of indexes of lower level and reference to objective law. In this way, we fully utilize the existing data and optimize high level index to make our model closer to reality.

\section{The Proposed Model}

3.1. Description of Timeline. First we assign different letters to the variables in favor of the later modeling (Table 1).

By searching quantity of NCAA participating teams of different years and conducting simple regression analysis, we get the curve graph in Figure 2 (Table 2). 
TABLE 2: Coefficients in Figure 2.

\begin{tabular}{ccccc}
\hline & \multicolumn{2}{c}{ Unstandardized Coefficients } & \multicolumn{2}{c}{ Standardized Coefficients } \\
& $B$ & Std. Error & Beta & $t$ \\
\hline (Constant) & -3729.584 & 116.622 & 0.954 & -31.980 \\
\hline
\end{tabular}

We can find from this graph that quantity of participating teams first experiences a fast rising section and then gradually decreases:

$$
y=a x+b .
$$

By applying Matlab, we get a model that basically fits this trend:

$$
y=2.015 x-3729.584,
$$

where $x$ is regression variable, that is, time.

Then we compute and find the fitting formula of participating teams, in which 2.015 is regression coefficient and other factors that influence $y$ are contained in random error -3929.584 .

After this, we optimize the winning rate, one of the indexes, by using relation between teams. It is easy to understand that competence of each team ascends with the participating team and so is level to win. With the data of winning rate of related team as reference and the optimization, now we can give better evaluation to coach. 1)

We assume the winning rate after optimization is (model

$$
Q=P+P * \frac{Z-Y}{Y} .
$$

Take John Wooden as an example. The middle year of his coaching career is 1961. Taking 1961 into $y=2.015 x-$ 3729.584 , we can get $Z=y=221.831$. We define year 1964 as the middle of the nearest century and gave 1964 into (2); we get $Y=227.876$. Giving $P, Z$, and $Y$ into (3), then we obtain $Q=0.783$. Repeat the above calculation and then finish Table 3.

Data of winning rate after optimization are as in Table 3.

\subsection{Description of Findings}

3.2.1. Data Preprocessing. First we search and gather over 3000 sets of data about different college coaches, including their coaching career length, individual award, winning rate under his or her lead, and team award. Then we remove those who can hardly be the top five due to their too short career or very low winning rate. Finally, we have minimized our database to 150 coaches.

Then we optimize data about award of coaches left and carry out a small-scale analysis hierarchy process (AHP). (Model 2) [21].

\section{(i) Presumption.}

(1) The evaluation of importance of award in this

\begin{tabular}{|c|c|c|c|c|}
\hline \multirow[b]{2}{*}{ Coach } & \multicolumn{2}{|c|}{ Attached list one } & \multirow[b]{2}{*}{$Z(y)$} & \multirow[b]{2}{*}{ Q } \\
\hline & Year & $P$ & & \\
\hline John Wooden & 1961 & 0.804 & 221.831 & 0.783 \\
\hline Adolph Rupp & 1951.5 & 0.822 & 202.689 & 0.731 \\
\hline Jim Calhoun & 1992.5 & 0.697 & 285.304 & 0.873 \\
\hline Mike Krzyzewski & 1995 & 0.764 & 290.341 & 0.973 \\
\hline Bob Knight & 1987 & 0.776 & 274.221 & 0.934 \\
\hline Dean Smith & 1979.5 & 0.793 & 259.109 & 0.902 \\
\hline Rick Pitino & 1996.5 & 0.706 & 293.364 & 0.909 \\
\hline Billy Donovan & 2004.5 & 0.710 & 309.484 & 0.964 \\
\hline Branch McCracken & 1952 & 0.750 & 203.696 & 0.670 \\
\hline Denny Crum & 1986.5 & 0.666 & 273.214 & 0.799 \\
\hline Hank Iba & 1950 & 0.731 & 199.666 & 0.641 \\
\hline Roy Williams & 2001.5 & 0.696 & 303.439 & 0.927 \\
\hline Jim Boeheim & 1995.5 & 0.756 & 291.349 & 0.967 \\
\hline Tubby Smith & 2003 & 0.790 & 306.461 & 1.062 \\
\hline Tom Izzo & 2005 & 0.774 & 310.491 & 1.055 \\
\hline Gary Williams & 1995 & 0.688 & 290.341 & 0.877 \\
\hline Jud Heathcote & 1983.5 & 0.740 & 267.169 & 0.868 \\
\hline Jerry Tarkanian & 1986 & 0.711 & 272.206 & 0.849 \\
\hline John Calipari & 2001.5 & 0.649 & 303.439 & 0.864 \\
\hline Jim Harrick & 1991.5 & 0.656 & 283.289 & 0.816 \\
\hline Al McGuire & 1971 & 0.693 & 241.981 & 0.736 \\
\hline Phog Allen & 1931 & 0.804 & 161.381 & 0.569 \\
\hline
\end{tabular}
approach is accurate.
TABle 3: Relevant data in optimization.

TABLE 4: Variable definitions mentioned in Model 2.

\begin{tabular}{lc}
\hline Items & Characters \\
\hline Winning rate & $Q$ \\
Individual honor & $M$ \\
Team honor & $N$ \\
Coaching career length & $U$ \\
Final score & $S$ \\
\hline
\end{tabular}

(2) The higher this value is, the bigger the influence on objectives hierarchy it has.

(ii) Definition of Factors. See Table 4.

(iii) Objective Level Assigns. See Table 5.

(iv) Comparison Matrix and Weight Calculation. We get two factors, $C_{i}$ and $C_{j}$, every time and define $a_{i j}$ as the ratio of $C_{i}$ and $C_{j}$. We can express all these results in pairwise comparison matrix [22]:

$$
A=\left(a_{i j}\right)_{n^{2}}, \quad a_{i j}>0, a_{j i}=\frac{1}{a_{i j}} .
$$


TABLE 5: Priority order evaluating different games.

\begin{tabular}{lc}
\hline Award & Importance level \\
\hline CREG & $C_{1}$ \\
NCAA & $C_{2}$ \\
FF & $C_{3}$ \\
NC & $C_{4}$ \\
\hline
\end{tabular}

After matrix $A$, we find the largest eigenvalue $\lambda_{\max }$ and its eigenvector $\omega$. We normalize $\omega$ and get the sequencing weight of $C_{2}, \ldots, C_{n}$.

In order to judge whether the inconsistency of $A$ stands within limits, we need to commit consistency examination.

Steps are as follows:

(1) computing consistency index CI:

$$
\mathrm{CI}=\frac{\lambda_{\max }-n}{n-1},
$$

(2) average random consistency index RI (Table 6),

(3) computing consistency index CR to formula (4),

$$
\mathrm{CR}=\frac{\mathrm{CI}}{\mathrm{RI}}
$$

When $\mathrm{CR}<0.1$, we reckon that matrix will pass consistency examination.

(v) Objective Hierarchy-Wise Quantization. We define $W$ as the objective hierarchy mark and $x$ as the rule hierarchy data. Computing formula is

$$
W=x_{1} \omega_{1}+x_{2} \omega_{2}+x_{3} \omega_{3}+x_{4} \omega_{4}
$$

(vi) Input Data and Get the Conclusion. Input data and get comparison matrix:

$$
A=\left(\begin{array}{llll}
1 & \frac{1}{2} & \frac{1}{3} & \frac{1}{5} \\
2 & 1 & \frac{1}{2} & \frac{1}{3} \\
3 & 2 & 1 & \frac{1}{2} \\
5 & 3 & 2 & 1
\end{array}\right) .
$$

See Table 7.

We can find that $\lambda=4.0145, \mathrm{CI}=0.0048$ from formulae (4), (5), and (6), while CR $=0.0054<0.1$; this result passes consistency examination.

After normalization, we find that $\omega_{1}=0.0882 ; \omega_{2}=$ $0.1570 ; \omega_{3}=0.2720$; and $\omega_{4}=0.4829$.

Using formula (5) to compute the final mark of each coach, data are as follows (Table 8).

\subsubsection{Model Building (Model 3)}

(i) Presumption. (1) Individual award begins from 1. (2) Quantization of each coach reflects his or her comprehensive competence.

(ii) Build Hierarchy Structure. The first hierarchy is objective $(O)$ : integrate optimum decision order.

The second is rule hierarchy $(C)$ : evaluation factors are as follows in order: team award, winning rate (optimized), and coaching career. They are taken as $C_{k}(k=1,2,3,4)$.

The third hierarchy is project: we define $N$ the person evaluated $(N \geq 2)$ and they are taken as $P_{n}(n=1,2, \ldots, N)$.

(iii) Determine the Weight of Rule Hierarchy to Objective Hierarchy and Examine its Consistency. After normalization of feature vector, we get the weight vector of $(C)$ to $(O)$.

(iv) Determine Weight of Project Hierarchy $(P)$ to Rule Hierarchy $(C)$. Build comparison matrix between project hierarchy $(P)$ and $(C): B_{K}=\left(b_{i, j}^{(k)}\right), b_{i, j}^{(k)}=\left(T_{i}^{(k)} / T_{J}^{(k)}\right)(i, j=$ $1,2, \ldots, N ; k=1,2, \ldots, N)$. Obviously matrix $B_{K}$ is of consistency.

We can normalize $B_{K}$ to find weight vector of $P$ to $C_{k}$, taken as

$$
W^{(k)}=\left(w_{1}^{(k)}, w_{2}^{(k)}, \ldots, w_{N}^{(k)}\right) \quad(k=1,2,3,4) .
$$

Obviously all $B_{K}$ have consistency. With its feature we can find its largest eigenvalue.

$\lambda_{\max }^{(k)}=N, \mathrm{CR}_{2}^{(k)}=0$ both are the eigenvectors of $\lambda_{\max }^{(k)}$. We can normalize them to find weight vector of $P$ to $C_{k}$, taken as

$$
W^{(k)}=\left(w_{1}^{(k)}, w_{2}^{(k)}, \ldots, w_{N}^{(k)}\right)^{T} \quad(k=1,2,3,4) .
$$

That is, find weight vector of $P$ to $C$, and ratio indicator of consistency is

$$
\mathrm{CR}_{2}=\sum_{K=1}^{4} \mathrm{CR}_{2}^{(k)}=0
$$

(v) Determine Combination Weight W of Project Hierarchy $(P)$ to Objective Hierarchy $(O)$. We have known that weight of $C$ to $O$ is $W_{1}$ and $P$ to $C$ is $W_{2}$, so weight of $P$ to $O$ is

$$
W=W_{1} * W_{2}=\left(w_{1}, w_{2}, \ldots, w_{N}\right)^{T}
$$

whose combination consistency ratio index is $\mathrm{CR}=\mathrm{CR}_{1}+$ $\mathrm{CR}_{2}=0.0054<0.1$. Thus combination weight $W$ can be the evidence for objective decision.

(vi) Input Data Comprehensive Order. Because of $w_{n}(n=$ $1,2, \ldots, N)$ in the combination weight $W=\left(w_{1}, w_{2}, \ldots, w_{N}\right)$ is the weight $W$ of contestant coach $P_{n}$ to objective hierarchy $(O)$; that is, $w_{n}$ shows aggregative indicator of contestant coach $P_{n}$.

Put them in order and then we get our resolution. 
TABLE 6: Index of RI while " $n$ " is different.

\begin{tabular}{ccccccccccc}
\hline$n$ & 1 & 2 & 3 & 4 & 5 & 6 & 7 & 8 & 9 & 10 \\
\hline RI & 0 & 0 & 0.58 & 0.90 & 1.12 & 1.24 & 1.32 & 1.41 & 1.45 & 1.49 \\
\hline
\end{tabular}

TABLE 7: Result of weight.

\begin{tabular}{cccccc}
\hline & $C_{1}$ & $C_{2}$ & $C_{3}$ & $C_{4}$ & Weight \\
\hline$C_{1}$ & 1 & $1 / 2$ & $1 / 3$ & $1 / 5$ & 0.0882 \\
$C_{2}$ & 2 & 1 & $1 / 2$ & $1 / 3$ & 0.1570 \\
$C_{3}$ & 3 & 2 & 1 & $1 / 2$ & 0.2720 \\
$C_{4}$ & 5 & 3 & 2 & 1 & 0.4829 \\
\hline
\end{tabular}

TABLE 8: Ranking result.

\begin{tabular}{lccccc}
\hline Coach & CREG & NCAA & FF & NC & $W$ \\
\hline John Wooden & 16 & 16 & 12 & 10 & 12.0162 \\
Adolph Rupp & 28 & 20 & 2 & 4 & 10.6766 \\
Jim Calhoun & 16 & 23 & 4 & 3 & 8.9613 \\
Mike Krzyzewski & 12 & 29 & 6 & 4 & 10.0464 \\
Bob Knight & 17 & 27 & 6 & 2 & 9.6892 \\
Dean Smith & 15 & 23 & 5 & 2 & 7.6514 \\
Rick Pitino & 11 & 28 & 5 & 3 & 7.0053 \\
Billy Donovan & 9 & 26 & 7 & 0 & 6.8662 \\
Branch McCracken & 11 & 30 & 4 & 1 & 6.7289 \\
Denny Crum & 16 & 13 & 11 & 0 & 7.5926 \\
Hank Iba & 13 & 28 & 7 & 1 & 7.5255 \\
\hline
\end{tabular}

TABLE 9: Varies data after normalization (basketball).

\begin{tabular}{lcccc}
\hline & $U$ & $N$ & $M$ & $Q$ \\
\hline John Wooden & 0.009 & 0.009 & 0.033 & 0.028 \\
Adolph Rupp & 0.012 & 0.009 & 0.005 & 0.025 \\
Mike Krzyzewski & 0.012 & 0.006 & 0.005 & 0.023 \\
Bob Knight & 0.011 & 0.008 & 0.005 & 0.022 \\
Jim Calhoun & 0.012 & 0.008 & 0.011 & 0.021 \\
Roy Williams & 0.009 & 0.004 & 0.005 & 0.018 \\
Dean Smith & 0.008 & 0.008 & 0.016 & 0.018 \\
Denny Crum & 0.012 & 0.008 & 0.005 & 0.017 \\
Ralph Miller & 0.010 & 0.007 & 0.005 & 0.017 \\
Rick Pitino & 0.013 & 0.005 & 0.022 & 0.016 \\
\hline
\end{tabular}

3.2.3. Substituting Data to Solve the Model. Take $N=$ 150. Use Matlab to make matrix from 150 samples of four indicators. Solve the weight of the solution layer to the guideline layer. Normalize the data (Table 9).

Using the weight of the solution layer to the guideline layer, find the weight of combination. (We omit the formula because the data is fussy.)

Rank the scores of each sample, comparing their priority [23] (Table 10).
TABLE 10: Comparison of priority (basketball).

\begin{tabular}{lccccc}
\hline Coach & $U$ & $N$ & $M$ & $Q$ & $S$ \\
\hline John Wooden & 29 & 0.672 & 6.000 & 12.016 & 0.024 \\
Adolph Rupp & 41 & 0.627 & 1.000 & 10.677 & 0.017 \\
Jim Calhoun & 40 & 0.751 & 2.000 & 8.961 & 0.015 \\
Mike Krzyzewski & 39 & 0.837 & 1.000 & 10.046 & 0.015 \\
Bob Knight & 36 & 0.803 & 1.000 & 9.689 & 0.015 \\
Dean Smith & 26 & 0.775 & 3.000 & 7.651 & 0.015 \\
Rick Pitino & 42 & 0.782 & 4.000 & 7.005 & 0.015 \\
Billy Donovan & 37 & 0.830 & 3.000 & 6.866 & 0.014 \\
Branch McCracken & 38 & 0.575 & 2.000 & 6.729 & 0.013 \\
Denny Crum & 41 & 0.687 & 1.000 & 7.593 & 0.013 \\
\hline
\end{tabular}

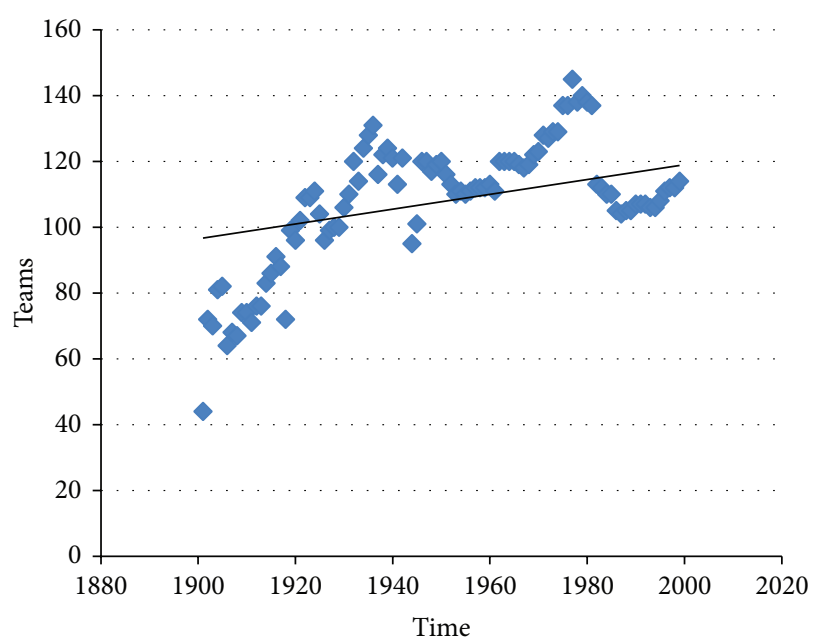

Figure 3: Curve of year and teams (football).

\section{Applications}

\subsection{Example A: Application of Football}

4.1.1. Timeline Influence. Using the above method fitting the number of teams and time, get the line (Figure 3 and Table 11).

\subsubsection{Model Application [24]}

(1) Data preprocessing: first, we also collected a lot of data, eliminated the project with obvious flaw, and thus selected 150 samples from 3000 teams from all over USA.

(2) Applying molds 2 and 3, we got the data (Tables 12 and 13).

Thus, we selected the top five "greatest coaches" (football). 
TABle 11: Coefficients in Figure 3.

\begin{tabular}{ccccr}
\hline & \multicolumn{2}{c}{ Unstandardized Coefficients } & Standardized Coefficients & $T$ \\
& $B$ & Std. Error & Beta & Sig. \\
\hline (Constant) & -331.208 & 79.890 & 0.464 & -4.146 \\
\hline
\end{tabular}

TABLE 12: Varies data after normalization (football).

\begin{tabular}{lcccc}
\hline$P$ & $U$ & $N$ & $M$ & $Q$ \\
\hline Joe Paterno & 0.016577 & 0.007846 & 0.025862 & 0.030626 \\
Bobby Bowden & 0.014414 & 0.007767 & 0.008621 & 0.027922 \\
Bear Bryant & 0.013694 & 0.007785 & 0.008621 & 0.020647 \\
Mack Brown & 0.01045 & 0.007158 & 0.00431 & 0.01662 \\
Tom Osborne & 0.009009 & 0.0087 & 0.00431 & 0.016413 \\
\hline
\end{tabular}

TABLE 13: Comparison of priority (football).

\begin{tabular}{lccccc}
\hline$P$ & $U$ & $N$ & $M$ & $Q$ & $S$ \\
\hline Joe Paterno & 46 & 0.756 & 6.000 & 16.803 & 0.024 \\
Bobby Bowden & 40 & 0.749 & 2.000 & 15.319 & 0.019 \\
Bear Bryant & 38 & 0.750 & 2.000 & 11.328 & 0.015 \\
Mack Brown & 29 & 0.690 & 1.000 & 9.119 & 0.012 \\
Tom Osborne & 25 & 0.839 & 1.000 & 9.005 & 0.012 \\
\hline
\end{tabular}

TABLE 14: Varies data after normalization (hockey).

\begin{tabular}{lcccc}
\hline$P$ & $U$ & $N$ & $M$ & $Q$ \\
\hline Jerry York & 0.0455 & 0.0313 & 0.0516 & 0.0922 \\
Red Berenson & 0.0341 & 0.0338 & 0.0323 & 0.078 \\
Bill Beaney & 0.0375 & 0.0355 & 0.0452 & 0.0745 \\
John "Snooks" Kelley & 0.0409 & 0.0339 & 0.0258 & 0.0603 \\
Mike McShane & 0.0364 & 0.0333 & 0.0387 & 0.0603 \\
\hline
\end{tabular}

TABLE 15: Comparison of priority (hockey).

\begin{tabular}{lccccc}
\hline$P$ & $U$ & $N$ & $M$ & $Q$ & $S$ \\
\hline Jerry York & 40 & 0.614 & 8.000 & 13.000 & 0.0686 \\
Bill Beaney & 33 & 0.697 & 7.000 & 10.500 & 0.0584 \\
Red Berenson & 30 & 0.663 & 5.000 & 11.000 & 0.057 \\
Mike McShane & 32 & 0.654 & 6.000 & 8.500 & 0.0489 \\
Jack Parker & 40 & 0.643 & 9.000 & 7.000 & 0.0477 \\
\hline
\end{tabular}

\subsection{Example B: Application of Hockey}

4.2.1. Data Preprocessing. Owing to limited data, 30 groups of hockey coaches were selected for the test. Because of the limited amount of actual data, the model was not suitable for the application in winning rate or may cause some errors.

4.2.2. Model Application. Applying models 2 and 3, we got the data as in Tables 14 and 15.

Thus, we selected the top five "greatest coaches" (hockey).

\section{Discussion and Conclusion}

The correction of the winning rate improves the influence of timeline, which means that there is a certain time having an influence on the coach's achievement. By applying the model, we have successfully elected five "best ever coaches" in different sports. Verified with network selection by coaches ranking model, we established our model with certain accuracy. It is obvious that there are advantages as follows.

(1) The Absence of Data. In the process of establishing and applying this model, we found that the following problems may be the cause. While developing the indicators, 360degree comprehensive assessment can ideally measure their professionalism and personal abilities. In addition to team honors, personal honors, coaching career length, and winning rate, some other indicators such as criminal records and other data can also measure their individual accomplishment. We believe that the evaluation of the best coaches lies not only in his achievements, but also in his personal qualities and charisma. Only in this way can we evaluate the coaches roundly.

In the definition of a formula to measure how the low level indicator affects the timeline, we hope to fit multivariate data with timeline includes the intense level of competition, people's attention on the events, state's financial investment in sports and data on media, and other technology development so that we can optimize the timeline overall.

Because of the lack of data, we selected the most important indicator-intense level of competition to optimize data through the definition of new formulas.

(2) Limited in Extension. We build model I as an example.

In the promotion of football, we obtain that $R^{2}=0.464$, indicating that the number of teams is less affected by time. Segmenting the function and then fitting in each part allow us to obtain a much more accurate function which is pretty close to the real data. Through access to information, we found that in 1933 the National Football League set up tournament for the first time, which greatly promoted the commercialization of sport. We speculate that this is also the reason why the number of teams peaked around 1930, while in 1940 a significant change in the rules occurred to American football competition. We speculate that this caused the number of participating teams to reach the minimum in the time period 1940-1945.

(3) Subjective Theories. When using AHP as a classic model, we cannot avoid our subjective opinions influencing the indicators. This obviously concludes our personal ideas and results in unavoidable error.

Although we cannot come up with a certain answer to the evaluation results of the best college coach through 
the use of the mathematical model described in this paper to select the best coach, we can generally conclude accurate result which matches the results online largely. Thus, we can consider that the model has a strong practicality. We consider that evaluating coaches in different aspects helps select the best coach for the team, making the team more competitive and excellent.

\section{Conflict of Interests}

The authors declare that there is no conflict of interests regarding the publication of this paper.

\section{References}

[1] K. Erickson, J. Côté, T. Hollenstein, and J. Deakin, "Examining coach-athlete interactions using state space grids: an observational analysis in competitive youth sport," Psychology of Sport and Exercise, vol. 12, no. 6, pp. 645-654, 2011.

[2] Q. Xu, "Coaches are the core elements of the development of sports," China Sports Coaches, no. 4, pp. 10-12, 2013.

[3] W. Chou, "Using AHP to assess a plan of training the adolescent golf player," in Proceedings of the 5th International Conference on Fuzzy Systems and Knowledge Discovery (FSKD '08), pp. 575579, Jinan, China, October 2008.

[4] A. Murphy, M. S. Kaufman, I. Molton, D. B. Coppel, J. Benson, and S. A. Herring, "Concussion evaluation methods among washington state high school football coaches and athletic trainers," PM and R, vol. 4, no. 6, pp. 419-426, 2012.

[5] E. Lunsford and C. T. Melear, "Using scoring rubrics to evaluate inquiry," Journal of College Science Teaching, vol. 34, pp. 34-38, 2004.

[6] J. Carpentier and G. A. Mageau, "The role of coaches'passion and athletes'motivation in the prediction of change-oriented feedback quality and quantity," Psychology of Sport and Exercise, vol. 15, no. 4, pp. 326-335, 2014.

[7] D. Gould, K. Collins, L. Lauer, and Y. Chung, "Coaching life skills through football: a study of award winning high school coaches," Journal of Applied Sport Psychology, vol. 19, no. 1, pp. $16-37,2007$.

[8] A. Abraham and D. Collins, "Examining and extending research in coach development," Quest, vol. 50, no. 1, pp. 59-79, 1998.

[9] P. E. Hartman, "Selecting the right person to be coach," NASSP Bulletin, vol. 62, no. 418, pp. 23-27, 1978.

[10] J. O. Segrave and C. A. Ciancio, "An observational study of a successful pop warner football coach," Journal of Teaching in Physical Education, vol. 9, no. 4, pp. 294-306, 1990.

[11] J. MacLean and D. Zakrajsek, "Factors considered important for evaluating Canadian University athletic coaches," Journal of Sport Management, vol. 10, no. 4, pp. 446-462, 1996.

[12] G. Bruno, E. Esposito, A. Genovese, and R. Passaro, "AHP-based approaches for supplier evaluation: problems and perspectives," Journal of Purchasing and Supply Management, vol. 18, no. 3, pp. 159-172, 2012.

[13] C. Hsu, C. Yang, T. Chen, and C. Chen, "Applying AHP method select online shopping platform," in Proceeding of the 7th International Conference on Service Systems and Service Management (ICSSSM '10), pp. 1-5, IEEE, Tokyo, Japan, June 2010.
[14] C. Wei, C. Chien, and M. J. Wang, "An AHP-based approach to ERP system selection," International Journal of Production Economics, vol. 96, no. 1, pp. 47-62, 2005.

[15] T. Selker, "Coach: a teaching agent that learns," Communications of the ACM, vol. 37, no. 7, pp. 92-99, 1994.

[16] I. M. Wycherley and E. Cox, "Factors in the selection and matching of executive coaches in organisations," Coaching, vol. 1, no. 1, pp. 39-53, 2008.

[17] Wikipedia, "List of college men's soccer coaches with 350 wins," 2013, http://en.wikipedia.org/wiki/List_of_college_men\%27s_soccer_coaches_with_350_wins.

[18] S. C. Basketball, "Coach index," 2013, http://www.sports-reference.com/cbb/coaches/.

[19] S. C. Football, "Coach index," 2013, http://www.sports-reference .com/cfb/coaches/.

[20] T. Wandzilak, C. J. Ansorge, and G. Potter, "Comparison between selected practice and game behaviors of youth sport soccer coaches," Journal of Sport Behavior, vol. 11, no. 2, pp. 78$88,1988$.

[21] S. Lipovetsky and W. Michael Conklin, "Robust estimation of priorities in the AHP," European Journal of Operational Research, vol. 137, no. 1, pp. 110-122, 2002.

[22] Z. Han, Methods and Application of Mathematical Modeling, Higher Education Press, Beijing, China, 2nd edition, 2009.

[23] Z. sinuany-Stern, "Ranking of sports teams via the ahp," Journal of the Operational Research Society, vol. 39, no. 7, pp. 661-667, 1988.

[24] P. Ling, "The developing course of NCAA league basketball tournament in the united states of America," Journal of Shandong Physical Education, vol. 17, no. 2, pp. 60-62, 2001. 


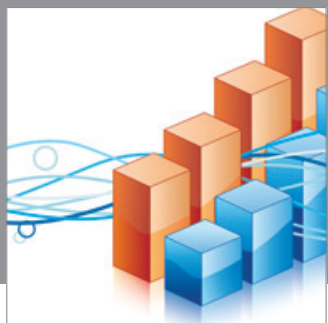

Advances in

Operations Research

mansans

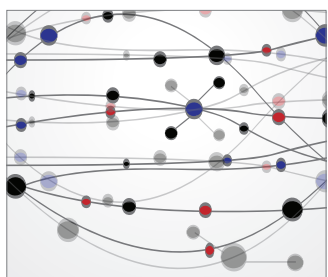

The Scientific World Journal
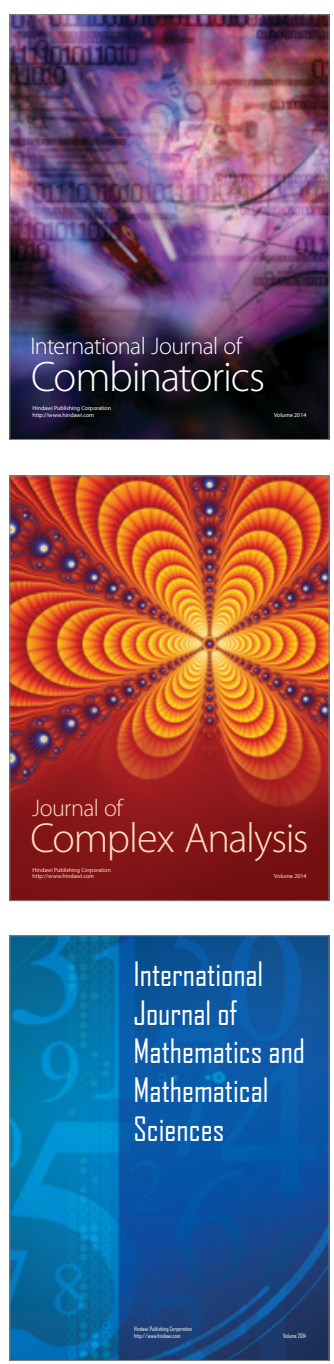
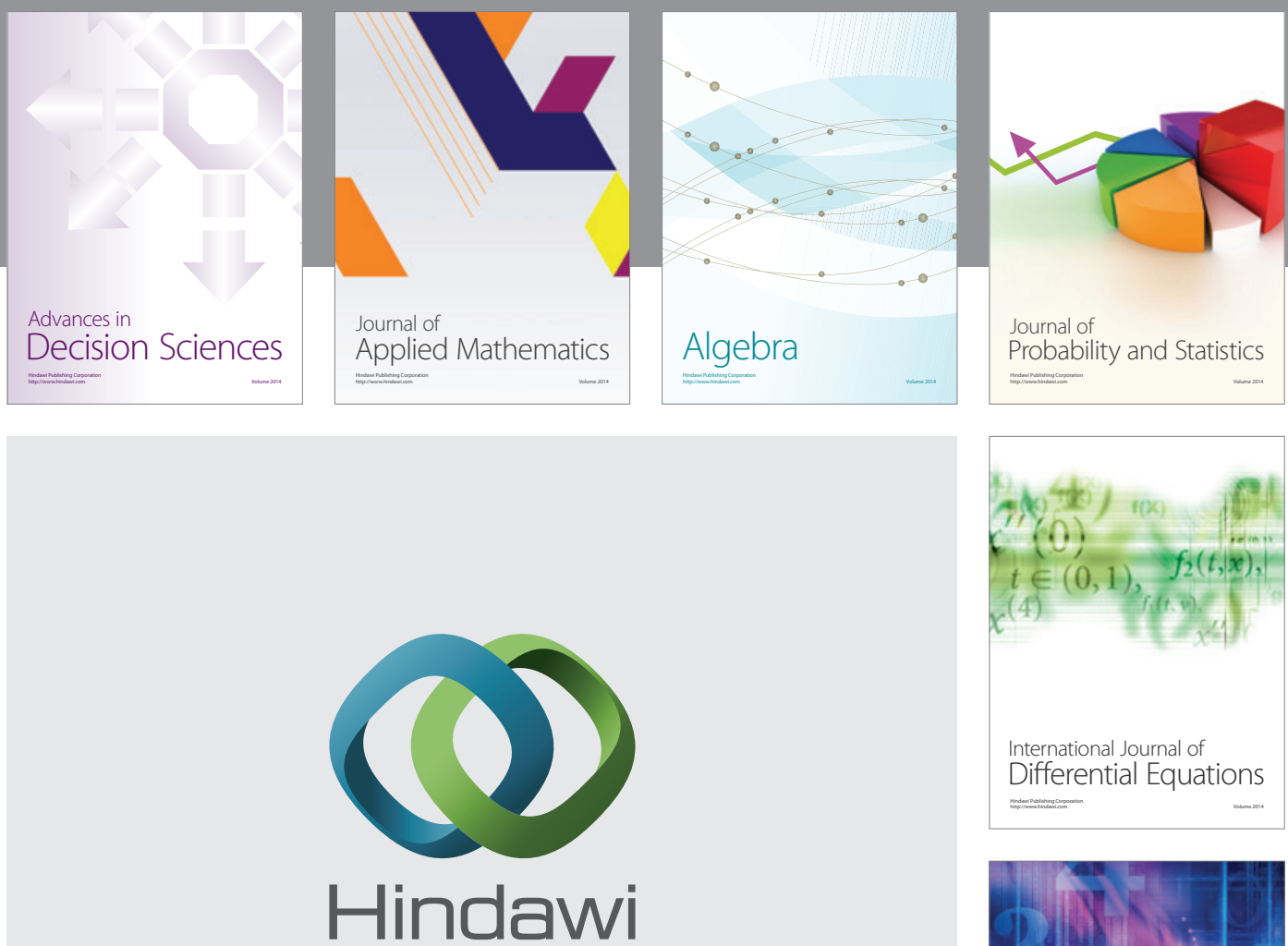

Submit your manuscripts at http://www.hindawi.com
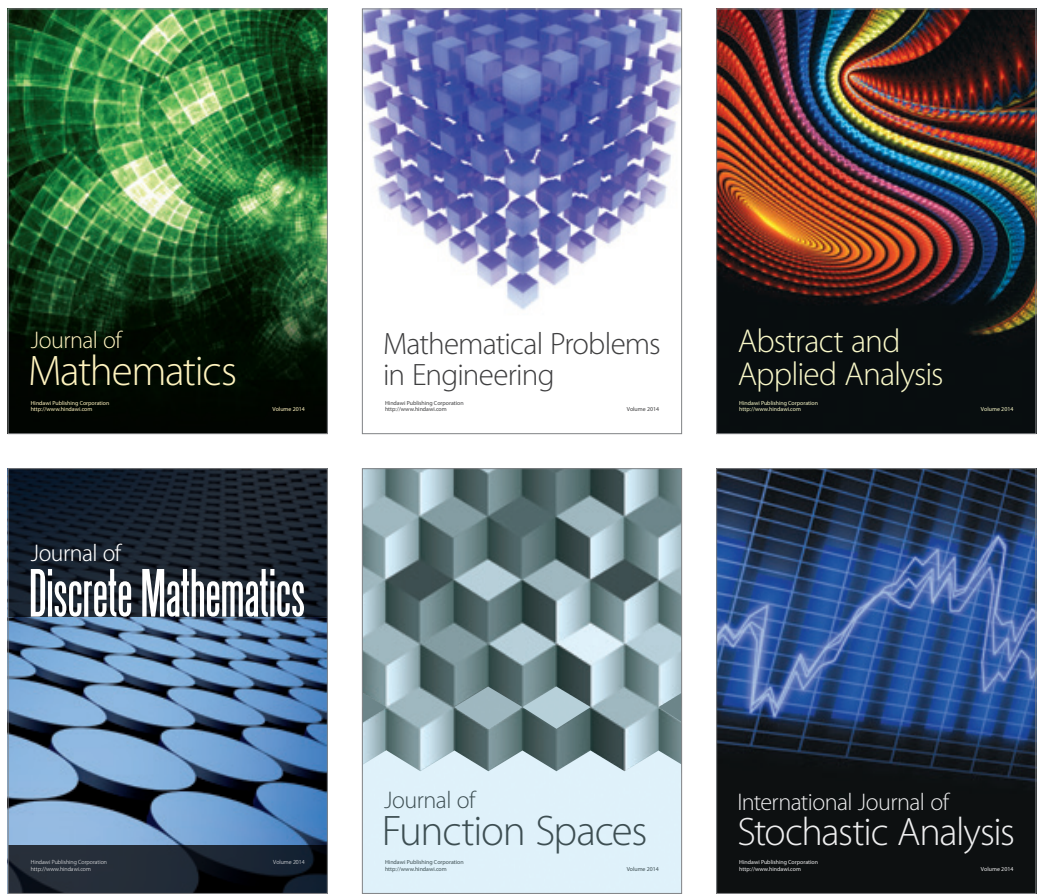

Journal of

Function Spaces

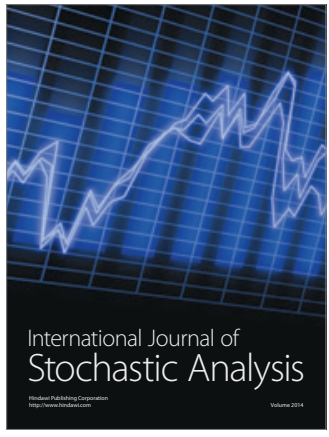

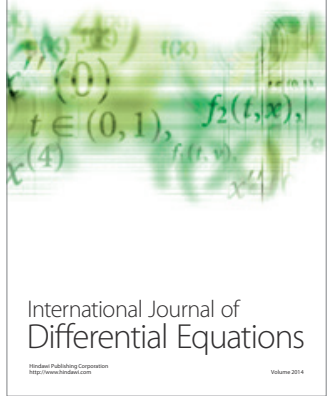
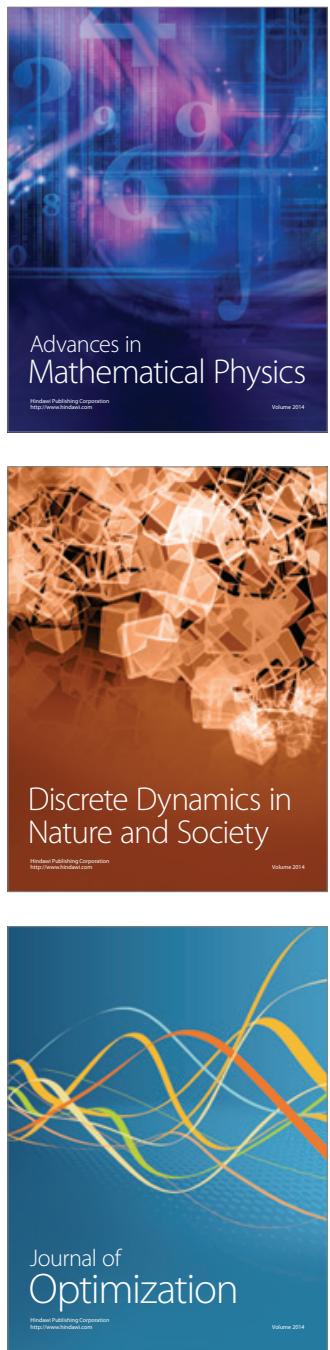